\title{
A NEW APPLICATION MODEL OF LEAN MANAGEMENT IN SMALL AND MEDIUM SIZED ENTERPRISES
}

\author{
Nguyen, D. M. \\ University of Economics and Business, Vietnam National University, Hanoi, Vietnam \\ E-Mail: nguyendangminh@hotmail.com
}

\begin{abstract}
Although Lean management has been implemented by Vietnamese small and medium sized enterprises (SMEs) for more than ten years, the success rate as well as the sustainable effectiveness achieved by these firms remains limited. As revealed by the survey, the current model of implementation mainly focuses on Lean management tools such as $5 \mathrm{~S}$, Kaizen (continuous improvement) and Mieruka (visual management). A better implementation model is proposed with the focus laid on the central factor of "Tam the"- a Vietnamese word refers to the deep understanding of employees and managers about the benefits of their tasks and Lean management for themselves. A simulation model run by Crystal Ball software confirms the higher effectiveness of the proposed model, which provides scientific evidence to persuade practitioners to swiftly employ the new model of implementation.

(Received in August 2014, accepted in October 2014. This paper was with the author 1 month for 1 revision.)
\end{abstract}

Key Words: Lean Management, Simulation, SMEs, "Tam the"

\section{INTRODUCTION}

Lean management is one of the most advanced management philosophies which focus on attaining customer's satisfaction and creating values through waste reduction $[1,2]$. The effectiveness and efficiency of Lean application is proven by numerous successful cases around the world including Toyota, Nissan, GM, Seven Eleven and etc. Specifically, implementing Lean management could help enterprises to reduce operating time by $50 \%$ and cost by $80 \%$, to save production space by $30 \%$ and to enhance the productivity by at least $30 \%[3,4]$.

Lean management has been implemented in many countries all over the world including Asian countries such as Thailand, China, Malaysia and Vietnam, etc. In those countries Lean management is applied in various fields ranging from manufacturing, retailing to health care service and education, etc. The method is becoming a new management trend in the $21^{\text {st }}$ century [5]. Lean management is translated into a variety of tools and techniques including 5S, Kaizen (continuous improvement), Mieruka (Visual management), JIT, Heijunka, TQM (Total Quality Management) and TPM (Total Productive Maintenance), etc. [6-8].

Despite their limited resources [9, 10], SMEs can implement Lean management successfully [11, 12]. Implementing Lean would help enterprises taking advantages of resources in order to improve production capacity and meet customer requirements [13]. Lean should be introduced into SMEs by using a set of basic tools which does not require a large investment such as 5S, Kaizen, Mieruka and flow balancing production, etc. [12, 14, 15].

In Vietnam, small and medium sized enterprises which account for $97 \%$ of the total number of enterprises [16] are playing a vital role in the development of the economy. However, Vietnamese SMEs have recently faced a lot of challenges as the consequence of the global financial crisis and the domestic economic slow-down; the number of dissolved SMEs has been constantly increasing since 2010 while the remaining SMEs have been struggling for survival [16]. Therefore, finding new management methods to increase the SMEs' 
productivity as well as the competitiveness is not only the mission of SMEs' managers but also of Vietnamese researchers.

The research aims to find out a better model of Lean implementation for Vietnamese SMEs. An AS-IS model reflects the current model of Lean implementation employed by Vietnamese SMESs; input of the model is collected from the SMEs' survey and in-depth interviews. A TO-BE model reflects the relationship between the newly proposed idea of "Tam the" (or "mind-set" in English) and the success degree of Lean implementation. To examine the reliability of the proposed model or the superiority of the TO-BE model over the AS-IS model, simulation method is employed. Simulation is a widely-known methodology in industry and engineering to reflect the nature of a process; it has also been used to verify the effectiveness of Lean's tools such as TQM [17].

\section{LITERATURE REVIEW}

Studies of successful Lean implementation have been conducted for many years; determinants of Lean application's effectiveness and the Leanness of enterprises have been recognized by scholars. For instance, [18] identified strong leadership and willingness to change the organizational culture as the two key factors which enable enterprises to implement Lean successfully. [19] conducted a quantitative study to find out determinants of Lean effectiveness among two independent variables of commitment to JIT and TQM, and four independent variables of quality of leadership, group problems solving, training and workers empowerment. The second branch in [19]'s research was production management. The authors examined the relationship among two dependent variables (including the degree of adoption of Lean production principles and degree of Leanness) and nine independent variables (including continuous improvement, multifunctional teams, and vertical information system, decentralized responsibilities, integrated functions, pull instead of push, zero defects and JIT). [20] identified three dimensions to measure the Leanness of management technique/systems, design methods/tools and production technology. In addition, [21] added five level of the Leanness which was awareness, sporadic implementation, formal implementation, complete implementation and continuous improvement.

The extant literature has commonly identified three successful factors for lean implementation which are the roles of leadership, people and culture of organization [22]. However, there has not been any model showing how to connect these factors together. The very first model about Lean implementation - "Lean Thinking Management Wheel" was formed with three main elements (people, technology and system) and seven supporting factors (customer voice/focus, people, culture, continuous improvement, built-in quality, standardization, and waste elimination) [22, 23]. Based on this wheel, [24] introduced "Lean Relative Weight Table" as the way to measure the aspects of Lean thinking methods or culture from which we derived the successful Lean manufacturing. However, [25], after reviewing Lean literature, figured out that the most apparent void within Lean literature was the lack of connections between Lean theory and Lean practicing.

In Vietnam, Lean implementing models have been shaped and practiced in manufacturing industries for about ten years and through four stages [26]; however, their effectiveness remains limited. This fact is illustrated by the number of SMEs implementing Lean being proportionally small and the failure rate of Lean implementation being quite high [27]. Besides, most of the SMEs face the question of how to sustain the effectiveness of Lean through time [28]. 


\section{RESEARCH PROCESS AND METHODOLOGY}

\subsection{Research process}

The research was developed through four steps. Firstly, the AS-IS model reflects the current Lean management application and it was constructed by reviewing the extant literature, surveying and interviewing industrial experts and business managers. Secondly, a new model of Lean management application in SMEs was proposed. Thirdly, the new model's reliability was confirmed with simulation method. At the final step, the model was re-confirmed via semi-structure interviews with industrial experts and business managers. The research methodology of this paper is described in Fig. 1.

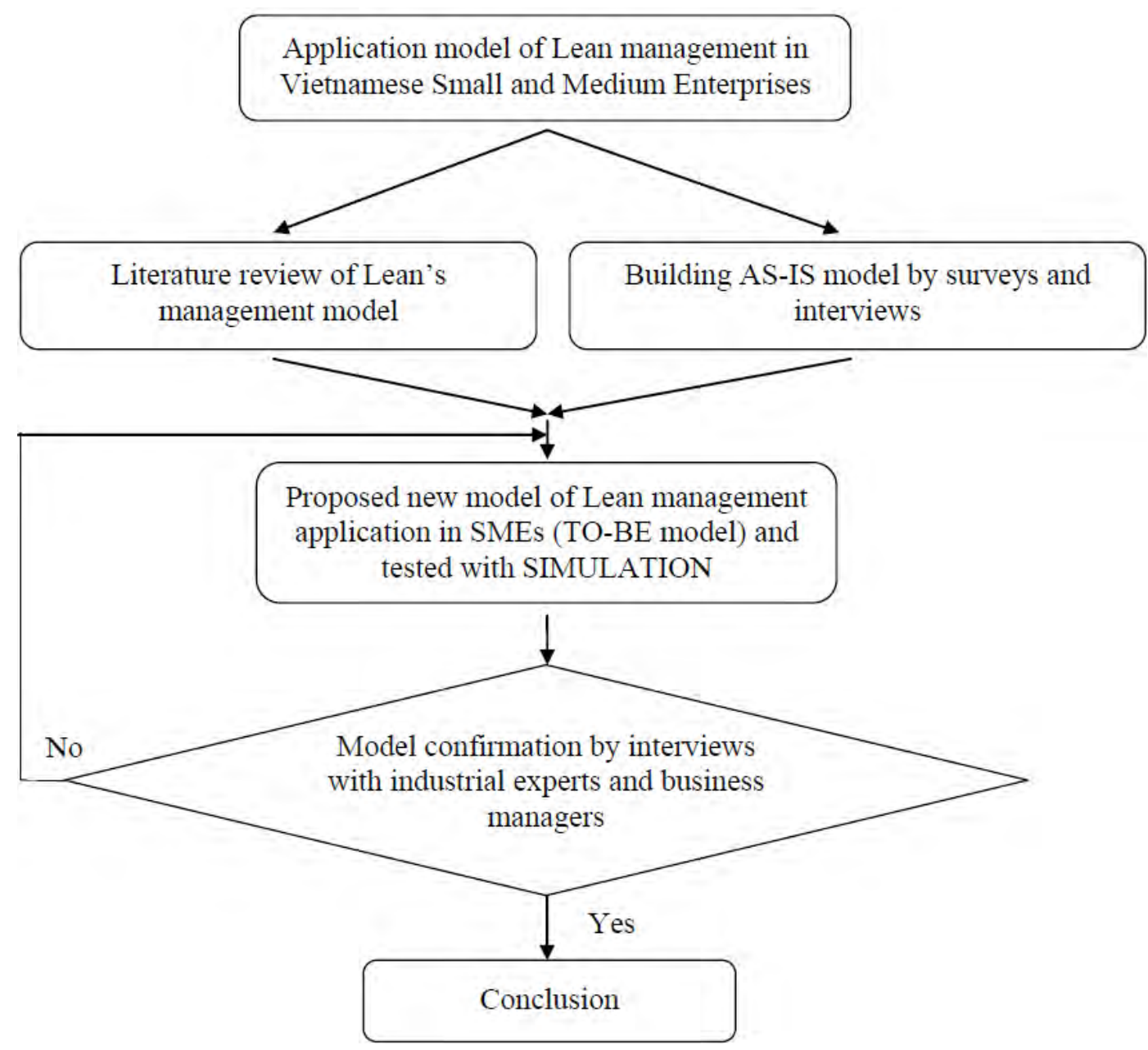

Figure 1: Research process.

\subsection{Research methodology}

To find out the model of Lean implementation currently employed by Vietnamese SMEs, the first round's survey and follow-up interviews were conducted with a sample of 150 SMEs operating in the supporting industries. These SMEs were listed among the most excellent enterprises by the statistical from Japan External Trade Organization (JETRO) in 2012 and 2013. The questionnaire of 75 multiple choice questions was designed to understand the current situation of Lean implementation in the surveyed SMEs; the follow- up interviews aimed to examine the difficulties and obstacles faced by these SMEs.

After the information was collected, the authors spent two months on interpreting the results and proposing a better model of implementation. The second round of survey, then, 
was conducted with the same sample. In this time, the questionnaire consists of 55 Likertscale questions to assess the influence of the newly proposed factor ("TAM THE") on the effectiveness of Lean implementation and SME's business performance. Information from this survey was subsequently used to build up TO-BE model and simulation model.

\section{CURRENT SITUATION OF LEAN MANAGEMENT IMPLEMENTATION IN VIETNAMESE SMES}

The first survey shows that most of the respondents are implementing $5 \mathrm{~S}$ (85.0\% of answers), Kaizen (44.0\% of answers) and Mieruka (29.6\% of answers). Therefore, the model describing the current situation (AS-IS model) includes three factors of $5 \mathrm{~S}$ implementing, Kaizen implementing and Mieruka implementing (Fig. 2). The equation of Lean effectiveness is assumed as:

where:

$$
Y_{0}=\mathrm{a} x+\mathrm{b} y+\mathrm{c} z+\varepsilon
$$

$Y_{0}$ - the effectiveness of Lean implementing,

$x$ - the level of $5 \mathrm{~S}$ implementing,

$y$ - the level of Kaizen implementing,

$z \quad$ - the level of Mieruka implementing.

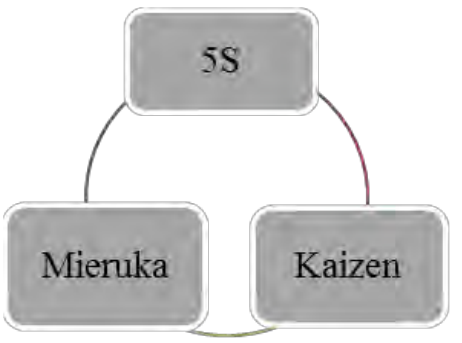

Figure 2: The current model of Lean management implementation (AS-IS model).

In the AS-IS model, the authors examined the relationship between three factors of the level of 5S, Kaizen and Mieruka implementing with the overall effectiveness of Lean implementation. In order to measure variables $x, y$ and $z$, the authors used information collected from the first survey. Each question represents one item of the level of 5S, Kaizen and Mieruka implementing as seen in Table I.

Listed items were validated with Cronbach Alpha and analysed with factor analysis method of EFA ${ }^{1}$. Then, the relationship between the independent and dependent variables was determined by the linear regression with the support of SPSS software. The regression result is presented in Table II and the regression equation as follows:

$$
Y_{0}=2.103+0.126 x+0.128 y+0.238 z+\varepsilon
$$

The regression model has the adjusted $R$-square of $35.7 \%$ and all the independent variables significantly explain the dependent variable. As the $R$-square is not as high as expected, the level of implementing 5S, Kaizen and Mieruka can only explain for $35.7 \%$ of changes in the overall effectiveness of Lean management at the surveyed companies. Additionally, the influence of each studied factor varies. In detail, the level of implementing Mieruka is the most influential factor; next comes the level of implementing of Kaizen and 5S. As stated previously, 5S is the most frequently applied method while Mieruka is the least one. This possibly indicates that the application of these methods have not been as effective as the investment of the companies.

\footnotetext{
${ }^{1}$ The Cronbach alpha and EFA results posed no matters for concerns and are available upon request.
} 
Table I: Items used to verify the current effectiveness of Lean management.

\begin{tabular}{|c|c|c|c|}
\hline No. & Item & Item's meaning & Variables \\
\hline 1 & VAR5S1 & Independent, $5 \mathrm{~S}$ 's practicing frequency & \multirow{5}{*}{$\begin{array}{l}\text { The variable " } x \text { " is } \\
\text { computed by the arithmetic } \\
\text { average of VAR5S1 to } \\
\text { VAR5S5 }\end{array}$} \\
\hline 2 & VAR5S2 & Independent, sorting standard & \\
\hline 3 & VAR5S3 & $\begin{array}{l}\text { Independent, employees' involvement in } \\
5 \mathrm{~S}\end{array}$ & \\
\hline 4 & VAR5S4 & $\begin{array}{l}\text { Independent, employees' understanding } \\
\text { of 5S's meaning }\end{array}$ & \\
\hline 5 & VAR5S5 & Independent, education duration of $5 \mathrm{~S}$ & \\
\hline 6 & VARKaizen1 & $\begin{array}{l}\text { Independent, employees' understanding } \\
\text { of Kaizen's meaning }\end{array}$ & \multirow{5}{*}{$\begin{array}{l}\text { The variable " } y \text { " is } \\
\text { computed by the arithmetic } \\
\text { average of VARKaizen } 1 \text { to } \\
\text { VARKaizen5 }\end{array}$} \\
\hline 7 & VARKaizen2 & $\begin{array}{l}\text { Independent, Kaizen 's promoting } \\
\text { policies }\end{array}$ & \\
\hline 8 & VARKaizen3 & Independent, Kaizen's suggestion forms & \\
\hline 9 & VARKaizen4 & Independent, Kaizen's suggestion process & \\
\hline 10 & VARKaizen5 & Independent, Kaizen's assessment criteria & \\
\hline 11 & VARVisual1 & Independent, visualization of strategy & \multirow{5}{*}{$\begin{array}{l}\text { The variable " } z \text { " is } \\
\text { computed by the arithmetic } \\
\text { average of VARVisuall to } \\
\text { VARVisual5 }\end{array}$} \\
\hline 12 & VARVisual2 & $\begin{array}{l}\text { Independent, visualization of operation } \\
\text { process }\end{array}$ & \\
\hline 13 & VARVisual3 & Independent, visualization of problems & \\
\hline 14 & VARVisual4 & Independent, visualization of solutions & \\
\hline 15 & VARVisual5 & $\begin{array}{l}\text { Independent, visualization of customers' } \\
\text { satisfaction }\end{array}$ & \\
\hline 16 & VARY01 & Dependent, reduction in production cost & \multirow{4}{*}{$\begin{array}{l}\text { The variable " } Y_{0} \text { " is } \\
\text { computed by the arithmetic } \\
\text { average of VARY01 to } \\
\text { VARY04 }\end{array}$} \\
\hline 17 & VARY02 & Dependent, reduction in delivery cost & \\
\hline 18 & VARY03 & $\begin{array}{l}\text { Dependent, reduction in } \\
\text { products' price }\end{array}$ & \\
\hline 19 & VARY04 & $\begin{array}{l}\text { Dependent, offering of cheaper price in } \\
\text { comparison with rivals }\end{array}$ & \\
\hline 20 & VARMindStaff1 & $\begin{array}{l}\text { Independent, employee's "Tam the" } \\
\text { (attitude toward their jobs) }\end{array}$ & \multirow{8}{*}{$\begin{array}{l}\text { The variable "Tam the" is } \\
\text { computed by the arithmetic } \\
\text { average of VARMindstaff1 } \\
\text { to VARMindsup4 (only this } \\
\text { variable's data were } \\
\text { collected from the second } \\
\text { survey) }\end{array}$} \\
\hline 21 & VARMindStaff2 & $\begin{array}{l}\text { Independent, employee's "Tam the" } \\
\text { (attitude toward lean activities) }\end{array}$ & \\
\hline 22 & VARMindStaff3 & $\begin{array}{l}\text { Independent, employee's "Tam the" (the } \\
\text { engagement with companies) }\end{array}$ & \\
\hline 23 & VARMindStaff4 & $\begin{array}{l}\text { Independent, employee's "Tam the" (the } \\
\text { educational level) }\end{array}$ & \\
\hline 24 & VARMindSup1 & $\begin{array}{l}\text { Independent, manager's "Tam the" (their } \\
\text { commitment toward lean activities) }\end{array}$ & \\
\hline 25 & VARMindSup2 & $\begin{array}{l}\text { Independent, manager's "Tam the" (their } \\
\text { understanding of lean management } \\
\text { activities) }\end{array}$ & \\
\hline 26 & VARMindSup3 & $\begin{array}{l}\text { Independent, manager's "Tam the" (their } \\
\text { openness for change) }\end{array}$ & \\
\hline 27 & VARMindSup4 & $\begin{array}{l}\text { Independent, manager's "Tam the" (their } \\
\text { participating and promoting attitude } \\
\text { toward lean activities) }\end{array}$ & \\
\hline
\end{tabular}


Table II: The regression result for the AS-IS model.

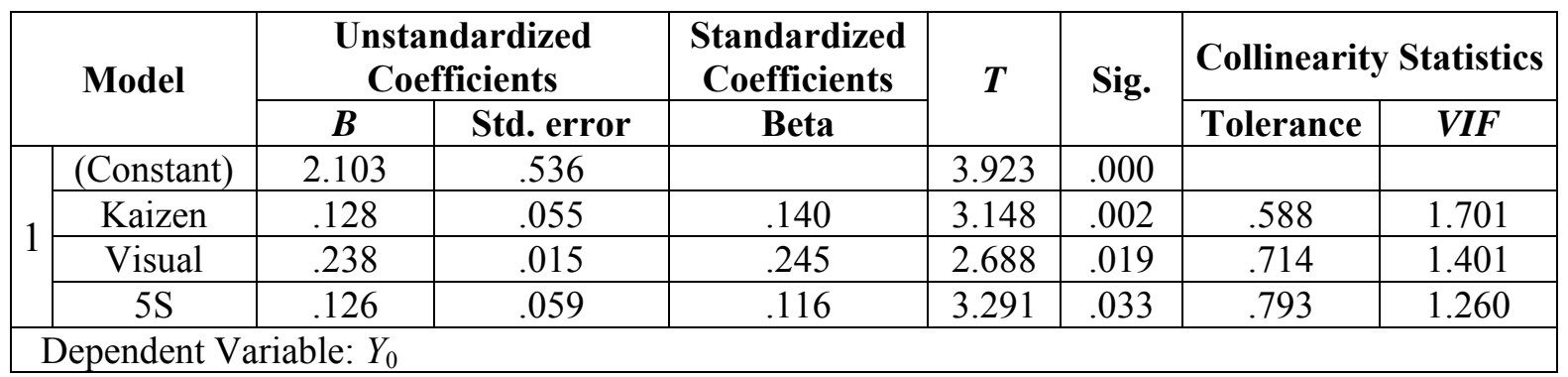

\section{THE PROPOSED MODEL}

When implementing Lean, SMEs should practice basic and less demanding financial requirement tools such as Kaizen, $5 \mathrm{~S}$ and visual control [14, 29]. After that, they can apply other tools including kanban, small slot size, etc. [30]. Besides, scholars around the world pointed out that people are the main driving force of the success of Lean implementation especially of Kaizen and 5S [22]. However, up to now, the specific relationship between human resources management and Lean practicing remains a void within the extant literature [25].

As revealed by the first survey and follow-up interviews, the major factor that prevents Vietnamese SMEs from sustaining Lean implementation's effectiveness is the human mindset and workers' behaviour. Therefore, the proposed model prioritizes the preparation of the mind-set for all people in the organization before starting Lean implementation. Thus, the core factor of the proposed model is "Tam the".

Implying more than the word "mind-set" "Tam the" is a Vietnamese phrase referring to the deep understanding of employees, workers and managers about the notion that their tasks will be initially beneficial for themselves. Workers with excellent "Tam the" would try their best to get the job well done because they understand that performing the job at the highest level brings them both explicit and implicit benefits. Hence, employees, workers and even managers look at their tasks through better and more positive viewpoints. "Tam the" would become a philosophy that affects not only the way people work, but also the way they live and behave in the society. The idea of the new model is to put "Tam the" at the centre which influences every other factor (Fig. 3).

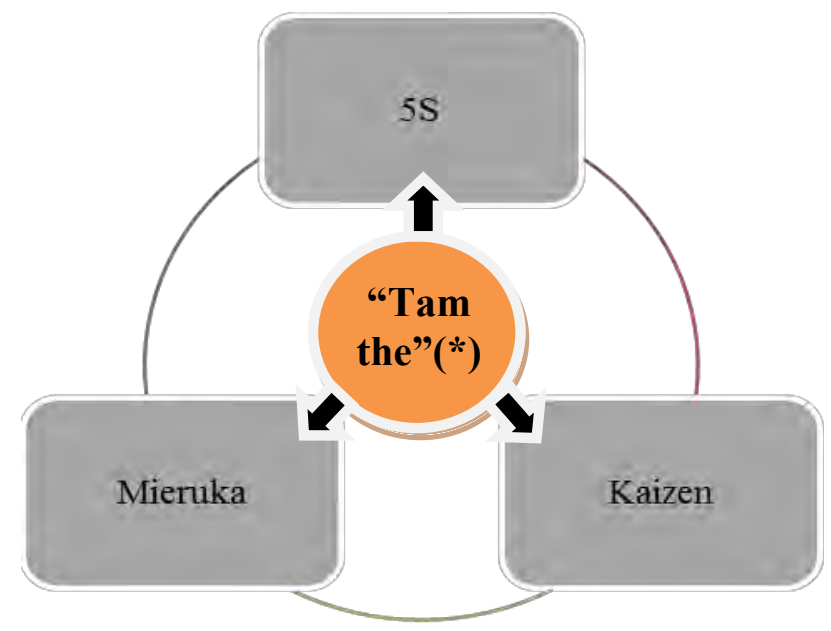

(*)"Tam the" refers to the deep understanding of people that the tasks they are performing benefit themselves. Thus, they will apply positive energv and best performance to their tasks.

Figure 3: The proposed model of Lean implementation (TO-BE model). 
Therefore, the new idea of "Tam the" is predicted to boost the degree of all factors. In the new model, the variable of "Tam the" is assumed as $\mathrm{M}$, and the new equation is:

where:

$$
Y_{1}=2.103+0.126 M_{x}+0.128 M_{y}+0.238 M_{z}+\varepsilon
$$

$Y_{1}$-the effectiveness of Lean implementation with the effect of $\mathrm{M}$,

$M_{x}$ - the implementation level of 5S with the effect of M,

$M_{y}$ - the implementation level of Kaizen with the effect of M,

$M_{z}$ - the implementation level of of Mieruka with the effect of M.

The coefficients of the eq. (3) was kept unchanged from the eq. (2) as the authors wished to separate the possible influence of the level of 5S, Kaizen and Mieruka implementing with the influence of "Tam the". Later on, the simulation method was applied to examine how the change of "Tam the" impacts the overall effectiveness of the Lean management.

To check the correctness of the TO-BE model, the authors conducted Monte Carlo Simulation (MCS); simulation and other statistical analysis methods have been proved to enhance the effectiviness of the production system [31]. MCS "relies on repeated random sampling and statistical analysis to compute the results" [32]. In this research, the authors followed the MCS's methodology suggested by [32] and [33]. The input variable for the simulation process is "Tam the" - "M" with values being collected from the second interview. The logical equation is the equation (3); $Y_{1}$ value is the model output which presents the effectiveness of Lean management implementation with "Tam the".

\section{MODEL TESTING AND RESULTS}

At the first step, function Fit in Crystal-Ball software was used to determine "Tam the" $-M$ 's distribution probability with its 150 historical data; $M$ has the uniform distribution.

In simulation setting, after 10,000 trials, the simulation result for $Y_{1}$ in forms of frequency charts and statistics are shown in Fig. 4 and in Table III.

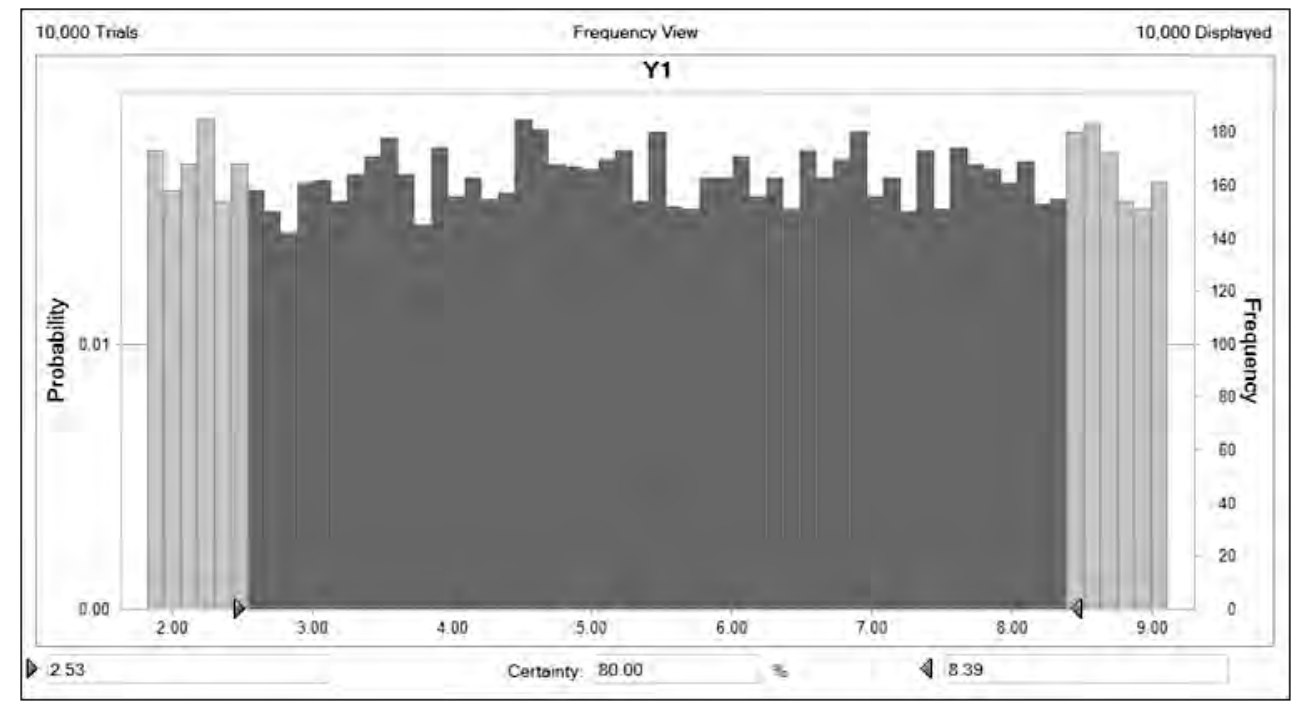

Figure 4: Simulation result for the effectiveness of Lean implementation with "Tam the" $\left(Y_{1}\right)$.

With "Tam the" being at the centre of the new model, the mean of $Y_{1}=5.47$ is much bigger than the mean of $Y_{0}=3.48$. Hence, at the time of testing 150 respondents, the effectiveness of Lean management implementation with "Tam the" is seen better than the result of Lean implementation without it. 
Table III: Forecasted values of $Y_{1}$.

\begin{tabular}{|l|c|}
\hline \multicolumn{1}{|c|}{ Content } & Values \\
\hline Base Case & 8.89 \\
\hline Mean & 5.47 \\
\hline Median & 5.46 \\
\hline Standard Deviation & 2.10 \\
\hline Variance & 4.42 \\
\hline Skewness & -0.0059 \\
\hline Kurtosis & 1.81 \\
\hline Coeff. of Variability & 0.3842 \\
\hline Minimum & 1.82 \\
\hline Maximum & 9.11 \\
\hline Mean Std. Error & 0.02 \\
\hline
\end{tabular}

The proposed model with "Tam the" and its simulation results were then presented in a focus group interview with 10 industrial experts and business managers. Most of the interviewees acknowledged that the lacking of "Tam the" in their current lean implementation models lead to their low success rate; thus, they highly appreciated the new model. Some of them planned to include "Tam the"s education and emphasis during their process of lean implementation right after the interviews. Additionally, the interviewees were quite fascinated at the evidence provided by the simulation method and Crystal Ball software; they also showed their eagerness to learn more about this method.

\section{CONCLUSION}

Due to the lack of a transformation model of Lean management for SMEs Vietnam [26], the initial purpose of this study was to propose the Lean implementation model suiting with the business and operating context of Vietnam. Recognizing the role of human resources development in the Lean implementation steps, the authors identified "Tam the" which refers to the deep understanding of people that the tasks they are performing benefit themselves as a leading factor. The effectiveness of the newly proposed model with "Tam the" was proven by both the simulation result and the focus group interviews with industrial experts and business managers. This implies that building up "Tam the" for all employees is a critical task of managers during the process of lean implementation in Vietnamese SMEs.

The paper contributes to the extant literature with a better model of lean implementation in the context of developing countries, particularly in Vietnam. The key idea which is also the novelty of the model revolves around the importance of "Tam the" thorough out the process of lean implementation. Regarding further research, the authors will collect more case studies to better demonstrate the effectiveness of the newly proposed model with both quantitative and qualitative methods as well as to specify different elements of "Tam the" needed in practice.

\section{REFERENCES}

[1] Womack, J. P.; Jones, D. T.; Roos, D. (2007). The Machine That Changed The World, Reprint edition, Free Press, New York

[2] Liker, J. K. (Ed.), (1999). Becoming Lean: Inside Stories of U. S. Manufacturers, Productivity, Inc., Portland 
[3] Lathin, D.; Mitchell R. (2001). Lean manufacturing: techniques, people and culture, Annual Quality Congress Proceedings, 321-325

[4] Ferdousi, F.; Ahmed, A. (2009). An investigation of manufacturing performance improvement through Lean production: A study on Bangladeshi garment firms, International Journal of Business and Management, Vol. 4, No. 9, 106-116, doi:10.5539/ijbm.v4n9p106

[5] Dankbaar, B. (1997). Lean production: denial, confirmation or extension of sociotechnical systems design?, Human Relations, Vol. 50, No. 5, 567-583, doi:10.1177/001872679705000505

[6] Braglia, M.; Carmignani, G.; Zammori, F. (2006). A new value stream mapping approach for complex production systems, International Journal of Production Research, Vol. 44, No. 18-19, 3929-3952, doi: $10.1080 / 00207540600690545$

[7] Salem, O.; Solomon, J.; Genaidy, A.; Minkarah, I. (2006). Lean construction: from theory to implementation, Journal of Management in Engineering, Vol. 22, No. 4, 168-175, doi:10.1061/ (ASCE)0742-597X(2006)22:4(168)

[8] Shah, R.; Ward. P. T. (2007). Defining and developing measures of lean production, Journal of Operations Management, Vol. 25, No. 4, 785-805, doi:10.1016/j.jom.2007.01.019

[9] Finch, B. (1986). Japanese management techniques in small manufacturing companies: A strategy for implementation, Production and Inventory Management, Vol. 27, No. 3, 30-38

[10] Lee, C. Y. (2004). TQM in small manufacturers: an exploratory study in China, International Journal of Quality \& Reliability Management, Vol. 21, No. 2, 175-197, doi:10.1108/ $\underline{02656710410516970}$

[11] Panizzolo, R. (1998). Applying the lessons learned from 27 lean manufacturers: The relevance of relationships management, International Journal of Production Economics, Vol. 55, No. 3, 223 240, doi:10.1016/S0925-5273(98)00066-8

[12] Lee, C. Y. (1997). JIT adoption by small manufacturers in Korea, Journal of Small Business Management, Vol. 35, No. 3, 98-107

[13] Golhar, D. Y.; Stamm, C. L.; Smith, W. P. (1990). JIT implementation in small manufacturing firms, Production and Inventory Management Journal, Vol. 31, No. 2, 44-47

[14] Gunasekaran, A.; Forker, L.; Kobu, B. (2000). Improving operations performance in a small company: a case study, International Journal of Operations \& Production Management, Vol. 20, No. 3, 316-336, doi:10.1108/01443570010308077

[15] Rothenberg, S.; Cost, F. (2004). Lean manufacturing in small and medium sized printers, Printing Industry Center at RIT, from http://scholarworks.rit.edu/cgi/viewcontent.cgi? article $=1014 \mathrm{\&}$ context $=$ books, accessed on 21-03-2014

[16] VCCI - The Vietnam Chamber of Commerce and Industry (2013). The Vietnam Annual Business Report

[17] Mohd Salleh, N. A.; Kasolang, S.; Jaffar, A. (2012). Simulation of integrated total quality management (TQM) with lean manufacturing (LM) practices in forming process using Delmia Quest, International Symposium on Robotics and Intelligent Sensors (IRIS 2012), published in Procedia Engineering, Vol. 41, 1702-1707, doi:10.1016/j.proeng.2012.07.371

[18] Day, J. C. (1995). The power of lean, Chief Executive magazine, from http://chiefexecutive.net/the-power-of-lean, accessed on 12-03-2014

[19] Soriano-Meier, H.; Forrester, P. L. (2002). A model for evaluating the degree of leanness of manufacturing firms, Integrated Manufacturing Systems, Vol. 13, No. 2, 104-109, doi:10.1108/ 09576060210415437

[20] Bohemia, E. (2002). Lean manufacturing and its impact on the role of industrial designers in Australia, Doctoral thesis, Faculty of the Built Environment, The University of New South Wales, from http://unsworks.unsw.edu.au/fapi/datastream/unsworks:548/SOURCE01, accessed on $03-03-2014$

[21] Greene, B. M. (2002). A taxonomy of the adoption of lean production tools and techniques, Doctoral dissertation, University of Tennessee, Knoxville, from http://trace.tennessee.edu/cgi/viewcontent. cgi? article $=3572 \&$ context $=$ utk_graddiss, accessed on 05-04-2014

[22] Cummings, R. (2004). A mathematical model to assess lean thinking manufacturing initiatives, Master thesis, College of Engineering, University of Hartford, Hartford

[23] Shetty, D. (2002). Design for Product Success, Society of Manufacturing Engineers, Dearborn 
[24] Shetty, D; Ali, A.; Cummings, R. (2010). Survey-based spreadsheet model on lean implementation, International Journal of Lean Six Sigma, Vol. 1, No. 4, 310-334, doi:10.1108/ 20401461011096087

[25] Stone, K. B. (2012). Four decades of lean: a systematic literature review, International Journal of Lean Six Sigma, Vol. 3, No. 2, 112-132, doi:10.1108/20401461211243702

[26] Nguyen, N. T. D; Bui, N. H. (2010). Lean manufacturing implementing in Vietnam - case studies, Journal of Development and Integration (Vietnam), Vol. 12, No. 8, 41-48

[27] Nguyen, D. M.; Do, T. C; Ta, H. G. (2013). 5S application in Vietnamese small and medium sized enterprises - current situation and solutions (in Vietnamese), Vietnam National University's Journal of Science, Economics and Business, Vol. 1, 24-32

[28] Nguyen, D. M.; Nguyen, L. C; Nguyen, D. T.; Tran, T. H. (2014). Orientation for the application of lean management among Vietnamese small and medium sized enterprises, Vietnam National University's Journal of Science, Economics and Business, Vol. 30, No. 1, 59-67

[29] Bonavia, T.; Marin, J. A. (2006). An empirical study of lean production in the ceramic tile industry in Spain, International Journal of Operations \& Production Management, Vol. 26, No. 5, 505-531, doi:10.1108/01443570610659883

[30] Rose, A. M. N.; Deros, B. Md.; Rahman, M. N. Ab.; Nordin, N. (2011). Lean manufacturing best practices in SMEs, Proceedings of the 2011 International Conference on Industrial Engineering and Operations Management, Kuala Lumpur, 872-877

[31] Bozickovic, R.; Radosevic, M.; Cosic, I.; Sokovic, M.; Rikalovic, A. (2012). Integration of simulation and lean tools in effective production systems - Case study, Strojniski vestnik Journal of Mechanical Engineering, Vol. 58, No. 11, 642-652, doi:10.5545/sv-jme.2012.387

[32] Raychaudhuri, S. (2008). Introduction to Monte Carlo simulation, Proceedings of the 2008 Winter Simulation Conference, 91-100, doi:10.1109/WSC.2008.4736059

[33] Nguyen, D. M.; Nguyen, H. M. T.; Nguyen, D. T. T; Nguyen., D. T. (2012). Equity valuation model of Vietnamese companies in a foreign securities market - A simulation approach, Proceedings of the 2012 Winter Simulation Conference, 1155-1166, doi:10.1109/WSC.2012. $\underline{6465014}$ 